\title{
OPEN Prevalence of anencephaly in Africa: a systematic review and meta-analysis
}

\author{
Mohammed Oumer ${ }^{1,2 \bowtie}$, Anteneh Ayelign Kibret ${ }^{1}$, Amanuel Girma ${ }^{1}$, Ashenafi Tazebew ${ }^{3}$ \& \\ Mezgebu Silamsaw4
}

Anencephaly is a severe anomaly of the brain that results from the failure of the cephalic part of the neural tube to close during the fourth week. It occurs at least in one per thousand births and is the major cause of fetal loss and disabilities in newborns. The objective of this review is to determine the birth prevalence of anencephaly in Africa. We identified relevant studies via a search of databases like PubMed Central, PubMed/Medline, Science Direct, Joanna Briggs Institute, African Journals Online, Embase, Google Scholar, Web of Science, and Cochrane Library. After examining the heterogeneity of studies via the Cochran $Q$ test and $I^{2}$ test (and Forest plot for visual inspection), the prevalence of anencephaly was estimated using the random-effect meta-analysis model. Consequently, we carried out subgroup, sensitivity, meta-regression, trim and fill, time-trend, and meta-cumulative analyses. In this systematic review and meta-analysis, the twenty-four studies reported a total of 4,963,266 births. The pooled birth prevalence of anencephaly in Africa was $0.14 \%(95 \% \mathrm{Cl}: 0.12,0.15 \%)$. Higher burden of anencephaly was detected in Ethiopia $(0.37 \%, \mathrm{Cl}: 0.15,0.58 \%)$, Algeria $(0.24 \%, \mathrm{Cl}: 0.24,0.25 \%)$, and Eritrea (0.19\%, $\mathrm{Cl}: 0.19,0.19 \%)$. The higher pooled prevalence of anencephaly was observed in the studies that included both live births and stillbirths (0.16\%) and in studies done after the year 2010 $(0.25 \%)$ whereas, the lower burden was detected among countries that had a mandatory folic acid fortification (0.05\%). High birth prevalence of anencephaly was detected in Africa. Strong prevention and control measures should be the priority because of an increment in the magnitude of anencephaly. Helping in prevention programs, which should be the ultimate contribution of this study to the field.

Anencephaly is a severe defect of the brain that results from failure of the rostral neuropore to close during the fourth week of development ${ }^{1-8}$. As a result, the vault of the cranium does not form, leaving the malformed neural tissue exposed. Later, this tissue degenerates, leaving a mass of necrotic tissue due to the abnormal structure and vascularization of the embryonic exencephalic neural tissue ${ }^{1-4}$. Sometimes, the closure abnormality of the tube extends caudally into the spinal cord and the malformation is known as craniorachischisis ${ }^{2,3}$.

Anencephaly, a common lethal anomaly, occurs in 1.0-4.7 per 1000 births and is more common in females (female: male ratio of 4:1) than in males ${ }^{1,3,4}$. It is the most common serious anomaly seen in stillborn fetuses. Newborns with this severe defect may survive after birth, but only for a short period ${ }^{1,4}$. Newborns delivered with anencephaly show persistent unconsciousness due to lack of functioning cerebral cortex and varying degrees of brain stem functions causing brain death ${ }^{4}$.

Anencephaly is always related to the absence of the calvaria ${ }^{1}$. An ossification abnormality in the bones of the cranium results in meningocele, meningoencephalocele, and meningohydroencephalocele ${ }^{2,5-7}$. The squamous part of the occipital bone is the most common malformed bone. Only meninges bulge through a small occipital bone opening, which is known as meningocele, but the part of the brain and part of the ventricle are protruding through the large defect in the skull, the defects are called meningoencephalocele and meningohydroencephalocele, respectively ${ }^{8-14}$. These malformations occur one in every two thousand births ${ }^{2,3}$.

It is the major cause of fetal loss and disabilities in newborns and it is considered a significant public health problem $^{4-6,15,16}$. It is associated with substantial mortality, morbidity, and psychological costs ${ }^{6-8}$.

\footnotetext{
${ }^{1}$ Department of Human Anatomy, School of Medicine, College of Medicine and Health Sciences, University of Gondar, Gondar, Amhara, Ethiopia. ${ }^{2}$ Department of Epidemiology, Institute of Public Health, College of Medicine and Health Sciences, University of Gondar, Gondar, Amhara, Ethiopia. ${ }^{3}$ Departments of Pediatrics and Child Health, School of Medicine, College of Medicine and Health Sciences, University of Gondar, Gondar, Amhara, Ethiopia. ${ }^{4}$ Department of Internal Medicine, School of Medicine, College of Medicine and Health Sciences, University of Gondar, Gondar, Amhara, Ethiopia. ${ }^{\circledR}$ email: mohammedoumer58@gmail.com
} 


\section{Identification of studies via databases}

\begin{tabular}{|c|c|}
\hline $\begin{array}{l}\text { Records identified from: } \\
\text { Databases }(\mathrm{n}=418) \\
\text { PubMed }(150), \text { Google Scholar } \\
(250) \text { and other databases }(18)\end{array}$ & \multirow[t]{2}{*}{$\begin{array}{l}\text { Records removed before screening: } \\
\text { Duplicate records removed }(n=99)\end{array}$} \\
\hline$\downarrow$ & \\
\hline $\begin{array}{l}\text { Records screened } \\
(\mathrm{n}=319)\end{array}$ & $\begin{array}{l}\text { Records excluded } \\
(\mathrm{n}=249)\end{array}$ \\
\hline$\downarrow$ & \\
\hline $\begin{array}{l}\text { Reports sought for retrieval } \\
(\mathrm{n}=70)\end{array}$ & $\begin{array}{l}\text { Reports not retrieved } \\
(\mathrm{n}=0)\end{array}$ \\
\hline$\downarrow$ & \\
\hline $\begin{array}{l}\text { Reports assessed for eligibility } \\
(\mathrm{n}=70)\end{array}$ & $\begin{array}{l}\text { Reports excluded (other than outcome of } \\
\text { interest }=14 \text { ): } \\
0 \quad \text { Lack of separate data/ composite }\end{array}$ \\
\hline 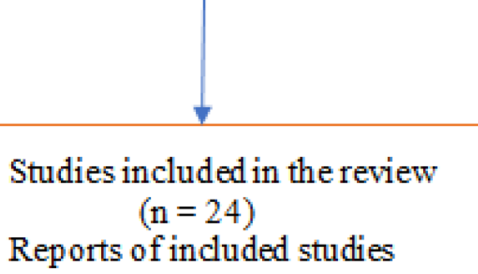 & $\begin{array}{l}\text { outcome } \\
\text { Not English, studies with insufficient } \\
\text { data about birth outcome } \\
\text { Data about types of NTD, but not } \\
\text { prevalence of anencephaly } \\
\text { Lack of outcome of interest }(n=32)\end{array}$ \\
\hline
\end{tabular}

Figure 1. Study selection flow diagram based on the PRISMA 2020 statement: an updated guideline for reporting systematic reviews ${ }^{19}$.

Anencephaly is suspected in utero when there is an elevated level of alpha-fetoprotein in the amniotic fluid. The abnormality can be diagnosed by ultrasonography and magnetic resonance imaging because extensive parts of the brain and the vault of the skull are absent ${ }^{1-3}$. Because anencephalic fetuses lack a swallowing reflex in the presence of a large defect (the fetus lacks the neural control for swallowing amniotic fluid, thus, the fluid does not pass into the intestines for absorption and subsequent transfer to the placenta for disposal), the last two months of pregnancy are characterized by polyhydramnios (excess amniotic fluid $)^{1,3}$.

Anencephaly, although it is preventable, is still the major cause of death and newborn disability in the world. It can be prevented by having women take $400 \mu \mathrm{g}$ of folic acid per day before and during pregnancy ${ }^{2,3,17,18}$.

This review is helpful to dig out the burden of anencephaly in Africa and provide valuable information to the government, policymakers, health professionals (Anatomists, Pediatricians, Medical students, for instance), researchers, communities, and Non-Governmental Organizations to play a role in reducing the burden, and making further research towards anencephaly. Furthermore, little is known about the magnitude of anencephaly in the region as a whole. Therefore, the aim of the present systematic review and meta-analysis is to determine the pooled birth prevalence of anencephaly in Africa.

\section{Results}

The comprehensive search of databases yielded four hundred eighteen studies about anencephaly in Africa. Of these, 99 were excluded because of duplication. Of the rest articles (319), 249 articles were excluded after reviewing the titles and abstracts. Full texts of the remaining 70 articles were screened and assessed for eligibility. Thus, twenty-four studies have fulfilled the inclusion criteria and have been included in the systematic review and meta-analysis (Fig. 1).

In this systematic review, twenty-four studies reported 4,963,266 births. All included studies were crosssectional $(n=17)$ and prospective cohort study design $(n=7)^{5-14,20-33}$. Studies conducted in Ethiopia $(n=5)^{5,9-11,14}$, Nigeria $(n=4)^{7,12,22,23}$, South Africa $(n=3)^{27,30,31}$, Algeria $(n=2)^{8,28}$, Sudan $(n=2)^{21,33}$, Tunisia, Eritrea, Democratic Republic (DR) Congo, Libya, Egypt, Ghana, Tanzania, and Cameron ${ }^{6,13,20,24-26,29,32}$ were identified (Table 1).

Surprisingly, all studies included were facility-based studies. Currently, Ethiopia has voluntary folic acid fortification whereas South Africa, Nigeria, Ghana, and Cameron have mandatory folic acid fortification with Wheat Flour, Maize Flour, and Rice. Studies considered after the implementation of mandatory folic acid fortification policy were South Africa and Nigeria (Table 2). 


\begin{tabular}{|c|c|c|c|c|c|c|}
\hline First author & Year & Country & Study design & Sample size & Duration (months) & Prevalence (\%) \\
\hline Gedefaw et al. ${ }^{5}$ & 2018 & Ethiopia & Cross-sectional & 8677 & 7 & 0.78 \\
\hline Nasri et al. ${ }^{6}$ & 2014 & Tunisia & Cross-sectional ${ }^{*}$ & $3,803,889$ & 240 & 0.005 \\
\hline Anyanwu et al. ${ }^{7}$ & 2015 & Nigeria & Cross-sectional & 1456 & 9 & 0.07 \\
\hline Houchar et al. ${ }^{8}$ & 2008 & Algeria & Cross-sectional $^{*}$ & 28,500 & 36 & 0.24 \\
\hline Berihu et al. $^{9}$ & 2018 & Ethiopia & Cross-sectional & 14,903 & 9 & 0.66 \\
\hline Taye et al. ${ }^{10}$ & 2019 & Ethiopia & Cross-sectional & 76,201 & 6 & 0.05 \\
\hline Abebe et al. ${ }^{11}$ & 2020 & Ethiopia & Cross-sectional & 45,951 & 60 & 0.14 \\
\hline Nnadi et al. ${ }^{12}$ & 2016 & Nigeria & Prospective & 10,163 & 36 & 0.05 \\
\hline Estifanos et al. ${ }^{13}$ & 2017 & Eritrea & Cross-sectional $^{*}$ & 39,803 & 24 & 0.19 \\
\hline Legesse et al. ${ }^{14}$ & 2019 & Ethiopia & Prospective & 956 & 7 & 0.21 \\
\hline Ahuka et al..$^{20}$ & 2006 & DR Congo & Cross-sectional $^{*}$ & 8824 & 96 & 0.011 \\
\hline Oumer et al. ${ }^{21}$ & 2016 & Sudan & Cross-sectional & 36,785 & 12 & 0.049 \\
\hline Alrede et al..$^{22}$ & 1992 & Nigeria & Prospective & 5977 & 36 & 0.033 \\
\hline Ekanem et al. ${ }^{23}$ & 2008 & Nigeria & Cross-sectional ${ }^{*}$ & 127,929 & 276 & 0.016 \\
\hline Singh et al. ${ }^{24}$ & 2000 & Libya & Prospective & 15,938 & 12 & 0.075 \\
\hline Mohammed et al. ${ }^{25}$ & 2011 & Egypt & Cross-sectional & 5000 & 7 & 0.02 \\
\hline Njamnshi et al. ${ }^{26}$ & 2008 & Cameron & Cross-sectional $^{*}$ & 52,710 & 120 & 0.008 \\
\hline Sayed et al. ${ }^{27}$ & 2008 & South Africa & Prospective & 53,000 & 9 & 0.037 \\
\hline Houcher et al. ${ }^{28}$ & 2012 & Algeria & Cross-sectional ${ }^{*}$ & 28,500 & 36 & 0.242 \\
\hline Anyebuno et al. ${ }^{29}$ & 1993 & Ghana & Cross-sectional $^{*}$ & 19,094 & 24 & 0.084 \\
\hline Venter et al. ${ }^{30}$ & 1995 & South Africa & Prospective & 10,380 & 40 & 0.171 \\
\hline Buccimazza et al. ${ }^{31}$ & 1994 & South Africa & Cross-sectional ${ }^{*}$ & 516,252 & 240 & 0.032 \\
\hline Kinasha et al. $^{32}$ & 2003 & Tanzania & Cross-sectional ${ }^{*}$ & 34,000 & 24 & 0.012 \\
\hline Elsheikh et al. ${ }^{33}$ & 2009 & Sudan & Prospective & 18,378 & 12 & 0.125 \\
\hline
\end{tabular}

Table 1. The characteristics of original studies included in the systematic review and meta-analysis, 2020. Key: ${ }^{\star}$ Cross-sectional study design with a retrospective review.

\begin{tabular}{|c|c|c|c|c|}
\hline First author & Setting & Prevalence period & Folic acid fortification policy & Birth outcome, denominator \\
\hline Gedefaw et al & Hospital-based & Feb 2016-Aug 2016 & Yes $^{*}$ & $\mathrm{LB}+\mathrm{SB}$ \\
\hline Nasri et al & Hospital-based & $1991-2011$ & No & $\mathrm{LB}+\mathrm{SB}$ \\
\hline Anyanwu et al & Hospital-based & Apr 2013-Dec 2013 & Yes & LB \\
\hline Houchar et al & Hospital-based & $2004-2006$ & No & $\mathrm{LB}+\mathrm{SB}$ \\
\hline Berihu et al & Hospital-based & Oct 2016-Jun 2017 & Yes $^{*}$ & $\mathrm{LB}+\mathrm{SB}$ \\
\hline Taye et al & Hospital-based & Jan 2015-Jul 2015 & Yes $^{*}$ & LB \\
\hline Abebe et al & Hospital-based & Sep 2011-Dec 2015 & Yes $^{*}$ & $\mathrm{LB}+\mathrm{SB}$ \\
\hline Nnadi et al & Hospital-based & Jan 2011-Dec 2013 & Yes & $\mathrm{LB}+\mathrm{SB}$ \\
\hline Estifanos et al & Hospital-based & Jan 2007-Aug 2011 & No & $\mathrm{LB}+\mathrm{SB}$ \\
\hline Legesse et al & Hospital-based & Oct 2018-Apr 2019 & Yes $^{*}$ & $\mathrm{LB}+\mathrm{SB}$ \\
\hline Ahuka et al & Hospital-based & Jan 1993-Aug 2001 & No & LB \\
\hline Oumer et al & Hospital-based & Aug 2014-Jul 2015 & No & $\mathrm{LB}+\mathrm{SB}$ \\
\hline Alrede et al & Hospital-based & Jun 1987-Jun 1990 & No & $\mathrm{LB}+\mathrm{SB}$ \\
\hline Ekanem et al & Hospital-based & $1980-2003$ & No & $\mathrm{LB}+\mathrm{SB}$ \\
\hline Singh et al & Hospital-based & $1995-1996$ & No & $\mathrm{LB}+\mathrm{SB}$ \\
\hline Mohammed et al & Hospital-based & Mar 2007-Oct 2007 & No & $\mathrm{LB}$ \\
\hline Njamnshi et al & Hospital-based & Jun 1997-Dec 2006 & No & $\mathrm{LB}+\mathrm{SB}$ \\
\hline Sayed et al & Hospital-based & Oct 2004-Jun 2005 & Yes & $\mathrm{LB}+\mathrm{SB}$ \\
\hline Houcher et al & Hospital-based & $2010-2012$ & No & $\mathrm{LB}+\mathrm{SB}$ \\
\hline Anyebuno et al & Hospital-based & Jan 1991-Dec 1992 & No & $\mathrm{LB}+\mathrm{SB}$ \\
\hline Venter et al & Hospital-based & Jun 1989-Dec 1992 & No & LB \\
\hline Buccimazza et al & Hospital-based & Jan 1973-Dec 1992 & No & $\mathrm{LB}+\mathrm{SB}$ \\
\hline Kinasha et al & Hospital-based & Jan 2000-Jan 2002 & No & LB \\
\hline Elsheikh et al & Hospital-based & Feb 2003-Jan 2004 & No & $\mathrm{LB}+\mathrm{SB}$ \\
\hline
\end{tabular}

Table 2. The summary of studies included in the systematic review and meta-analysis, 2020. Key: LB: Live births; SB: Stillbirths; ${ }^{*}$ : Voluntary folic acid fortification. 


\begin{tabular}{|c|c|c|c|c|c|c|c|c|c|c|}
\hline Studies & $\begin{array}{l}\text { Appropriate } \\
\text { sampling } \\
\text { frame? }\end{array}$ & $\begin{array}{l}\text { Appropriate } \\
\text { sampling? }\end{array}$ & $\begin{array}{l}\text { Adequate } \\
\text { sample size? }\end{array}$ & $\begin{array}{l}\text { Detail setting } \\
\text { description? }\end{array}$ & $\begin{array}{l}\text { Analysis with } \\
\text { sufficient } \\
\text { coverage? }\end{array}$ & $\begin{array}{l}\text { Valid method } \\
\text { to identify the } \\
\text { condition? }\end{array}$ & $\begin{array}{l}\text { Reliable } \\
\text { measurement? }\end{array}$ & $\begin{array}{l}\text { Appropriate } \\
\text { statistical } \\
\text { analysis? }\end{array}$ & $\begin{array}{l}\text { Adequate } \\
\text { response } \\
\text { rate? }\end{array}$ & $\begin{array}{l}\text { Total, out } \\
\text { of } 9\end{array}$ \\
\hline Gedefaw et al & Yes & Yes & Yes & Yes & Yes & Yes & Yes & Yes & N/A & 9 \\
\hline Nasri et al & Yes & N/A & Yes & Yes & Yes & $\mathrm{UC}$ & UC & Yes & N/A & 7 \\
\hline Anyanwu et al & N/A & N/A & Yes & Yes & Yes & Yes & Yes & Yes & $\mathrm{N} / \mathrm{A}$ & 9 \\
\hline Houchar et al & Yes & N/A & Yes & UC & Yes & No & No & Yes & $\mathrm{N} / \mathrm{A}$ & 6 \\
\hline Berihu et al & N/A & Yes & Yes & Yes & Yes & Yes & Yes & Yes & Yes & 9 \\
\hline Taye et al & $\mathrm{N} / \mathrm{A}$ & N/A & Yes & Yes & Yes & No & Yes & Yes & Yes & 8 \\
\hline Abebe et al & Yes & N/A & Yes & Yes & Yes & No & Yes & Yes & $\mathrm{N} / \mathrm{A}$ & 8 \\
\hline Nnadi et al & Yes & N/A & Yes & Yes & Yes & Yes & Yes & Yes & $\mathrm{N} / \mathrm{A}$ & 9 \\
\hline Estifanos et al & Yes & N/A & Yes & No & No & Yes & No & Yes & No & 5 \\
\hline Legesse et al & Yes & No & Yes & Yes & No & No & Yes & Yes & No & 5 \\
\hline Ahuka et al & Yes & N/A & Yes & Yes & Yes & Yes & UC & UC & N/A & 7 \\
\hline Oumer et al & Yes & N/A & Yes & Yes & Yes & Yes & UC & Yes & N/A & 8 \\
\hline Alrede et al & Yes & N/A & Yes & UC & UC & UC & UC & Yes & N/A & 5 \\
\hline Ekanem et al & Yes & N/A & Yes & No & Yes & UC & No & Yes & N/A & 6 \\
\hline Singh et al & Yes & N/A & Yes & Yes & Yes & Yes & UC & Yes & N/A & 8 \\
\hline $\begin{array}{l}\text { Mohamme- } \\
\text { detal }\end{array}$ & N/A & N/A & Yes & Yes & Yes & Yes & UC & Yes & N/A & 8 \\
\hline Njamnshi et al & Yes & N/A & Yes & Yes & Yes & UC & No & Yes & $\mathrm{N} / \mathrm{A}$ & 7 \\
\hline Sayed et al & Yes & N/A & Yes & No & Yes & UC & No & Yes & $\mathrm{N} / \mathrm{A}$ & 6 \\
\hline Houcher et al & Yes & $\mathrm{N} / \mathrm{A}$ & Yes & UC & Yes & UC & No & Yes & $\mathrm{N} / \mathrm{A}$ & 6 \\
\hline $\begin{array}{l}\text { Anyebuno } \\
\text { et al }\end{array}$ & Yes & N/A & Yes & Yes & Yes & UC & No & Yes & N/A & 7 \\
\hline Venter et al & Yes & $\mathrm{N} / \mathrm{A}$ & Yes & Yes & Yes & Yes & UC & Yes & $\mathrm{N} / \mathrm{A}$ & 8 \\
\hline $\begin{array}{l}\text { Buccimazza } \\
\text { etal }\end{array}$ & Yes & N/A & Yes & Yes & Yes & UC & No & UC & N/A & 6 \\
\hline Kinasha et al & Yes & N/A & Yes & No & Yes & UC & No & Yes & N/A & 6 \\
\hline Elsheikh et al & $\mathrm{N} / \mathrm{A}$ & N/A & Yes & No & UC & UC & No & Yes & $\mathrm{N} / \mathrm{A}$ & 5 \\
\hline
\end{tabular}

Table 3. The quality status of studies based on JBI critical appraisal checklist for studies reporting prevalence data, 2020. Key: UC: Unclear, N/A: Not Applicable. N/A for appropriate sampling means the study included all participants rather than sampling methods; N/A for adequate response rate means the study considered all recorded cases from all participants, so it is adequate; UC means it may be considered but not explicitly stated in the manuscript. For adequate sample size, as all participants were included in the study during the study period, we considered an adequate sample size even if they did not calculate sample size (it is a total coverage).

Each study was evaluated using the JBI critical appraisal checklist for prevalence studies, it has nine questions/ items with options of Yes, No, Unclear, or Not Applicable (Table 3). The quality assessment grading for all items was based on the JBI descriptions for each item (methodological guidance for systematic reviews of epidemiological studies reporting the prevalence data). The quality score of each study was described in Table $3^{5-14,20-33}$.

Meta-analyses. In the present meta-analysis, the pooled birth prevalence of anencephaly was $0.14 \%$ or 1.4 per 1000 births ( $95 \%$ CI: $0.12,0.15 \%$ ) (Fig. 2). For all studies ${ }^{5-14,20-33}$, the median (per 100) value of birth anencephaly was $0.06 \%$ and the inter-quartile range was between 0.03 and 0.18 . The minimum and maximum values of birth anencephaly were 0.005 and $0.78 \%$, respectively.

Meta-analyses were performed to estimate the birth prevalence of anencephaly based on the study country, study design, birth outcome, period prevalence, and folic acid fortification status. High pooled prevalence of anencephaly was detected in Ethiopia 0.37\% (95\% CI: 0.15, 0.58\%), Algeria 0.24\% (CI: 0.24, 0.25\%), and Eritrea 0.19\% (CI: 0.19, 0.19\%) (Table 4).

The pooled birth prevalence of anencephaly for cross-sectional was $0.15 \%$ (95\% CI: $0.13,0.17 \%)$ and for prospective cohort design was $0.10 \%(95 \%$ CI: $0.07,0.13 \%)\left(P\right.$ value $\left.<0.001, \mathrm{I}^{2}=99.8-100 \%\right)$.

The pooled birth prevalence of anencephaly for live births (LB) only (contain six studies) was $0.06 \%(95 \%$ CI: $0.03,0.08 \%)$ and for both live birth and stillbirths (LB + SB) (contain eighteen studies) was $0.16 \%$ (95\% CI: $0.15,0.18 \%$ ) (Fig. 3).

Considering two prevalence periods ( $>2010$ and $\leq 2010$ years), the pooled prevalence of anencephaly for studies done after 2010 (contain nine studies) was 0.25\% (95\% CI: 0.15, 0.35\%) and for studies done before 2010 (contain fifteen studies) was $0.07 \%$ (95\% CI: 0.06, 0.08\%) (Fig. 4).

Even if their publication year is after the year 2010 (Nasri et al., Estifanos et al., and Mohammed et al.), most of their study period were found before 2010, so we categorized them as studies done before 2010. Based on four periods, the pooled prevalence of anencephaly for the period after 2010 (contain nine studies) was $0.25 \%$ ( $95 \%$ CI: $0.15,0.35 \%$ ), for the period between 1991 and 2011 was $0.0 \%$ (only one study done for 20 years), for 


\begin{tabular}{|c|c|c|c|c|c|}
\hline $\begin{array}{l}\text { First } \\
\text { author }\end{array}$ & Year & & & ES $(95 \% \mathrm{Cl})$ & $\begin{array}{l}\% \\
\text { Weight }\end{array}$ \\
\hline Gedefaw etal. & 2018 & & - & $0.78(0.77,0.79)$ & 4.15 \\
\hline Nasri et al. & 2014 & 1 & & $0.00(0.00,0.01)$ & 4.20 \\
\hline Anyanwu et al. & 2015 & $\bullet$ & & $0.07(0.06,0.08)$ & 4.08 \\
\hline Houchar et al. & 2008 & i & & $0.24(0.24,0.24)$ & 4.18 \\
\hline Berihu etal. & 2018 & & - & $0.66(0.65,0.67)$ & 4.16 \\
\hline Taye et al & 2019 & 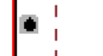 & & $0.05(0.05,0.05)$ & 4.20 \\
\hline Abebe et al. & 2020 & i & & $0.14(0.14,0.14)$ & 4.19 \\
\hline Nnadi et al. & 2016 & $\bullet !$ & & $0.05(0.05,0.05)$ & 4.19 \\
\hline Estifanos et al. & 2017 & : & & $0.19(0.19,0.19)$ & 4.19 \\
\hline Legesse et al. & 2019 & 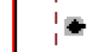 & & $0.21(0.18,0.24)$ & 3.76 \\
\hline Ahuka et al. & 2006 & 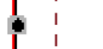 & & $0.01(0.01,0.01)$ & 4.20 \\
\hline Oumer et al. & 2016 & * & & $0.05(0.05,0.05)$ & 4.20 \\
\hline Alrede et al. & 1992 & 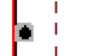 & & $0.03(0.03,0.04)$ & 4.19 \\
\hline Ekanem et al. & 2008 & $\begin{array}{l}1 \\
\\
\end{array}$ & & $0.02(0.02,0.02)$ & 4.20 \\
\hline Singh et al. & 2000 & $\bullet 1$ & & $0.08(0.07,0.08)$ & 4.19 \\
\hline Mohammed etal. & 2011 & 1 & & $0.02(0.02,0.02)$ & 4.19 \\
\hline Njamnshi et al. & 2008 & 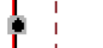 & & $0.01(0.01,0.01)$ & 4.20 \\
\hline Sayed et al. & 2008 & - i & & $0.04(0.04,0.04)$ & 4.20 \\
\hline Houcher et al. & 2012 & $1 *$ & & $0.24(0.24,0.25)$ & 4.18 \\
\hline Anyebuno et al. & 1993 & $\bullet$ & & $0.08(0.08,0.09)$ & 4.19 \\
\hline Venter et al. & 1995 & t & & $0.17(0.16,0.18)$ & 4.16 \\
\hline Buccimazzaetal. & 1994 & ci & & $0.03(0.03,0.03)$ & 4.20 \\
\hline Kinasha et al. & 2003 & 1 & & $0.01(0.01,0.01)$ & 4.20 \\
\hline Elsheikh et al. & 2009 & 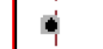 & & $0.13(0.12,0.13)$ & 4.19 \\
\hline Overall (I-squared & $d=100.0 \%, p=0.000)$ & 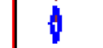 & & $0.14(0.12,0.15)$ & 100.00 \\
\hline
\end{tabular}

Figure 2. Forest plot showing the pooled prevalence of anencephaly in Africa, 2020.

\begin{tabular}{|l|l|l|}
\hline S. No & Country & Prevalence of anencephaly \% (95\% CI) \\
\hline 1 & Ethiopia & $0.37(0.15,0.58)$ \\
\hline 2 & Tunisia & $0.005(0.005,0.005)$ \\
\hline 3 & Nigeria & $0.04(0.02,0.06)$ \\
\hline 4 & Algeria & $0.24(0.24,0.25)$ \\
\hline 5 & Eritrea & $0.19(0.19,0.19)$ \\
\hline 6 & DR of Congo & $0.01(0.009,0.01)$ \\
\hline 7 & Sudan & $0.09(0.01,0.16)$ \\
\hline 8 & Libya & $0.08(0.07,0.08)$ \\
\hline 9 & Egypt & $0.02(0.016,0.02)$ \\
\hline 10 & Cameron & $0.008(0.007,0.009)$ \\
\hline 11 & South Africa & $0.079(0.05,0.11)$ \\
\hline 12 & Ghana & $0.084(0.08,0.09)$ \\
\hline 13 & Tanzania & $0.01(0.01,0.013)$ \\
\hline Total & D + L pooled & $0.14(0.12,0.15)$ \\
\hline
\end{tabular}

Table 4. The pooled prevalence of anencephaly among African countries, 2020. The Der Simonian and Laird's $(\mathrm{D}+\mathrm{L})$ method was considered for significant heterogeneity between countries $\left(P<0.001, \mathrm{I}^{2}=99-100 \%\right)$. 


\begin{tabular}{|c|c|c|c|c|}
\hline \multicolumn{3}{|l|}{$\begin{array}{l}\text { First } \\
\text { author }\end{array}$} & \multirow[t]{2}{*}{ ES $(95 \%$ Cl) } & \multirow[t]{2}{*}{$\begin{array}{l}\% \\
\text { Weight }\end{array}$} \\
\hline \multicolumn{3}{|l|}{$\mathrm{LB}+\mathrm{SB}$} & & \\
\hline Gedefaw etal. & 2018 & i. & $0.78(0.77,0.79)$ & 4.15 \\
\hline Nasri et al. & 2014 & 6 & $0.00(0.00,0.01)$ & 4.20 \\
\hline Houchar et al. & 2008 & 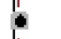 & $0.24(0.24,0.24)$ & 4.18 \\
\hline Berihu etal. & 2018 & $1 \cdot$ & $0.66(0.65,0.67)$ & 4.16 \\
\hline Abebe et al. & 2020 & 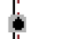 & $0.14(0.14,0.14)$ & 4.19 \\
\hline Nnadi et al. & 2016 & li & $0.05(0.05,0.05)$ & 4.19 \\
\hline Estifanos et al. & 2017 & Th & $0.19(0.19,0.19)$ & 4.19 \\
\hline Legesse et al. & 2019 & 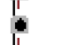 & $0.21(0.18,0.24)$ & 3.76 \\
\hline Oumer et al. & 2016 & 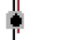 & $0.05(0.05,0.05)$ & 4.20 \\
\hline Alrede et al. & 1992 & 6 & $0.03(0.03,0.04)$ & 4.19 \\
\hline Ekanem et al. & 2008 & $!$ & $0.02(0.02,0.02)$ & 4.20 \\
\hline Singh et al. & 2000 & 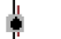 & $0.08(0.07,0.08)$ & 4.19 \\
\hline Njamnshi et al. & 2008 & 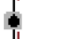 & $0.01(0.01,0.01)$ & 4.20 \\
\hline Sayed et al. & 2008 & 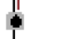 & $0.04(0.04,0.04)$ & 4.20 \\
\hline Houcher et al. & 2012 & 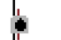 & $0.24(0.24,0.25)$ & 4.18 \\
\hline Anyebuno et al. & 1993 & 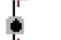 & $0.08(0.08,0.09)$ & 4.19 \\
\hline Buccimazzaetal. & 1994 & i & $0.03(0.03,0.03)$ & 4.20 \\
\hline Elsheikh et al. & 2009 & i. & $0.13(0.12,0.13)$ & 4.19 \\
\hline \multicolumn{3}{|c|}{ Subtotal ( $(-$-squared $=100.0 \%, p=0.000)$} & $0.16(0.15,0.18)$ & 74.97 \\
\hline \multicolumn{5}{|l|}{ in } \\
\hline Anyanwu et al. & 2015 & 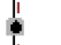 & $0.07(0.06,0.08)$ & 4.08 \\
\hline Taye et al & 2019 & $\phi$ & $0.05(0.05,0.05)$ & 4.20 \\
\hline Ahuka et al. & 2006 & 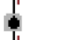 & $0.01(0.01,0.01)$ & 4.20 \\
\hline Mohammed etal. & 2011 & 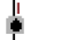 & $0.02(0.02,0.02)$ & 4.19 \\
\hline Venter et al. & 1995 & T. & $0.17(0.16,0.18)$ & 4.16 \\
\hline Kinasha et al. & 2003 & 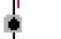 & $0.01(0.01,0.01)$ & 4.20 \\
\hline \multicolumn{3}{|c|}{ Subtotal (l-squared $=99.8 \%, p=0.000)$} & $0.06(0.03,0.08)$ & 25.03 \\
\hline \multicolumn{3}{|c|}{ Overall (l-squared $=100.0 \%, p=0.000)$} & $0.14(0.12,0.15)$ & 100.00 \\
\hline \multicolumn{5}{|c|}{ NOTE: Weights are from random effects analysis } \\
\hline & & $\| 1$ & & \\
\hline
\end{tabular}

Figure 3. Sub-group analysis showing the pooled prevalence of anencephaly based on birth outcome (live births only (LB), live births and stillbirths (LB+SB)) in Africa, 2020.

the period between 2000 and 2010 (contain seven studies) was $0.09 \%$ (95\% CI: 0.05, 0.13\%), and for the period before 2000 (contain seven studies) was $0.06 \%$ (95\% CI: 0.05, 0.07\%). Based on folic acid fortification policy $(P$ value $<0.001, \mathrm{I}^{2}=100 \%$ ), the pooled birth prevalence of anencephaly for countries that had a mandatory folic acid fortification (like Nigeria and South Africa) was lower, 0.05\% (95\% CI: 0.04, 0.06\%), than for those free of a mandatory folic acid fortification policy, $0.15 \%$ (95\% CI: $0.13,0.17 \%)$.

Using meta-regression analysis (multivariable), sample size $\left(\mathrm{B}\right.$-Coefficient $=-9.14 \mathrm{e}^{-09}, P$ value $\left.=0.888\right)$, year of publication $(\mathrm{B}$-Coefficient $=-0.004, P$ value $=0.589)$, duration of the study in month $(\mathrm{B}$-Coefficient $=-0.001$, $P$ value $=0.117)$, the JBI quality score $(B$-Coefficient $=-0.031, P$ value $=0.509)$, study country $(\mathrm{B}$-Coefficient $=-0.012, P$ value $=0.508)$, study design $(B-C o e f f i c i e n t=-0.195, P$ value $=0.110)$, folic acid fortification status (B-Coefficient $=-0.151, P$ value $=0.290)$, outcome status $(B-C o e f f i c i e n t=-0.176, P$ value $=0.103)$, and period prevalence $(B-C o e f f i c i e n t=0.016, P$ value $=0.915)$ were analyzed for the source of heterogeneity. None of them was statistically significant. Nevertheless, at bivariate analysis, study country (B-Coefficient $=-0.021$, $P$ value $=0.038)$, folic acid fortification status (B-Coefficient $=-0.167, P$ value $=0.045)$, and period prevalence (B-Coefficient $=-0.179, P$ value $=0.026)$ were significant at below 0.05 .

In this review, most of the studies had a uniform influence on the overall estimation of meta-analysis except two studies conducted in Ethiopia in 2018, which had some influence over other studies ${ }^{5,9}$ (Fig. 5).

The time trend analysis displayed the relationship between the birth prevalence of anencephaly and publication year from $1992(0.03 \%)$ to 2020 (0.14\%). In this trend in Africa, the highest peak of anencephaly in prevalence was observed between 2016 and 2018 (Fig. 6).

The present review described the cumulative effect of the birth prevalence of anencephaly from the year 1992 (0.03\%) to the year 2020 (0.14\%) (Fig. 7 ).

Based on the Funnel plot, considerable publication bias was observed (Fig. 8).

As a result, we conducted the trim and fill meta-analyses to adjust this bias. We analyzed thirty-seven studies (thirteen studies were filled) in the fill meta-analyses and the pooled birth prevalence of anencephaly using the 


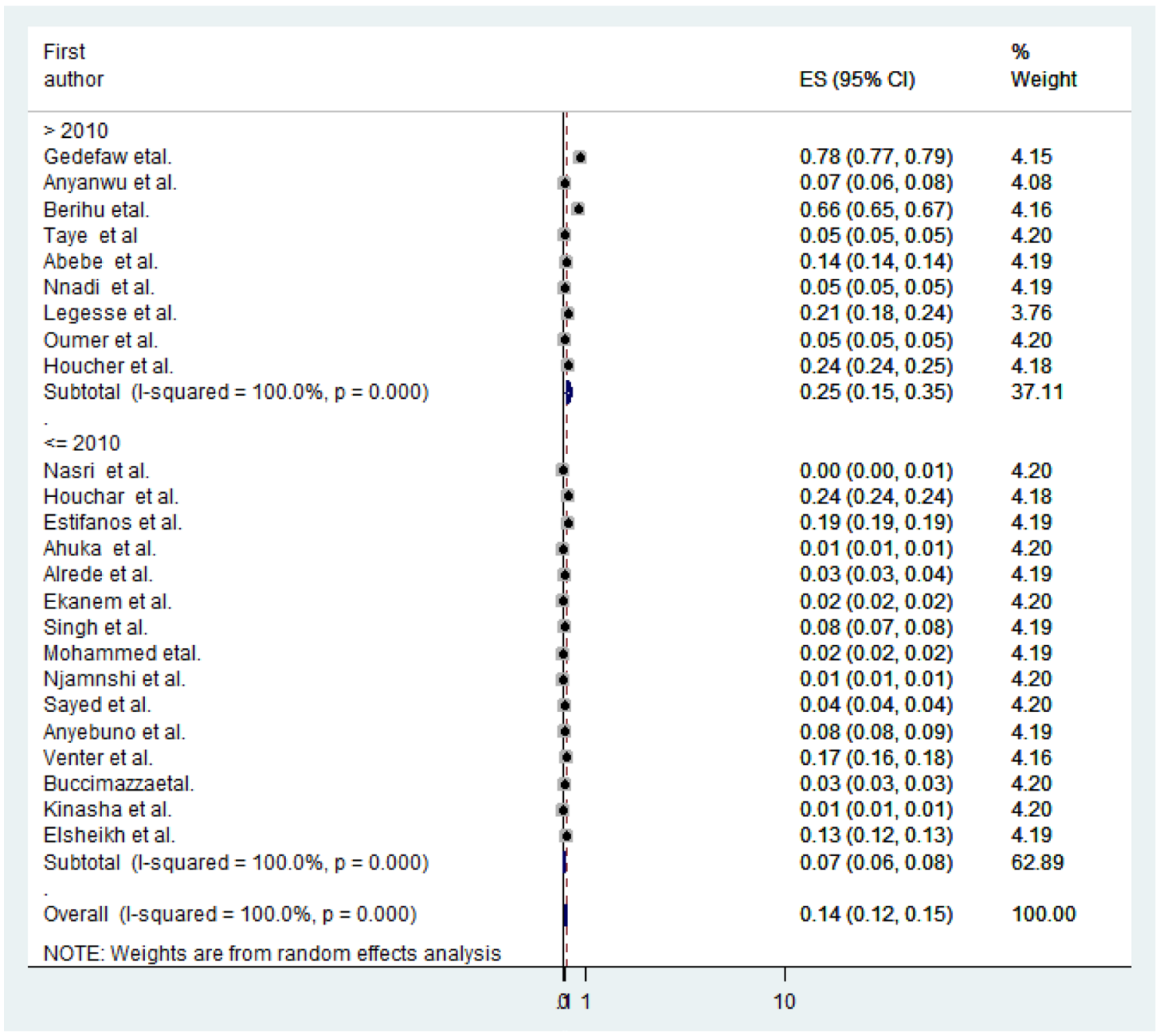

Figure 4. Sub-group analysis showing the pooled prevalence of anencephaly based on period prevalence in Africa, 2020.

random-effect model was $0.012 \%(95 \%$ CI: $-0.005,0.03 \%)$ (Fig. 9). This adjusted estimate suggested a lower risk of bias than the original analysis.

\section{Discussion}

The present systematic review and meta-analysis were carried out to determine the pooled birth prevalence of anencephaly in Africa. The burden of anencephaly seems to become decreasing due to different preventive measures and folic acid fortifications in high-income countries. In Africa, the hidden burden of anencephaly was very high and the primary data research, as well as systematic review and meta-analysis that show this burden, were so scarce. Even in the global estimation of the burden, the inclusion of studies from Africa was a few to represent the whole continent due to different reasons. Nevertheless, the effects of the anomaly correlate with mortality, disability, and psychological costs. It is an important public health problem that can be prevented with folic acid supplementation and fortification of staple foods ${ }^{1-3,17,18,34,35}$. Thus, the evidence provided a birth prevalence estimate in Africa. The pooled birth prevalence of anencephaly was $0.14 \%$, ranging from $0.12 \%$ to $0.15 \%$ (or 1.4 per 1000 births). This finding is comparable with the review conducted globally that estimates the live birth prevalence of anencephaly was $0.03 \%$ with the range of 0.008 to $0.11 \%{ }^{34}$. In addition, the review reported an estimate based on all pregnancies resulting in live births, stillbirths, and terminations were $0.103 \%$ for anencephaly. This review result suggested that low-and middle-income countries were mostly affected by this anomaly each year $^{34}$. However, the review did not include studies from Africa except for two studies, and representativeness for Africa has decreased for this reason. A systematic review in India reported the prevalence of anencephaly, which was $0.21 \%$, ranging from 0.16 to $0.28 \%{ }^{15}$. Our finding was supported by the previous evidence that indicated anencephaly is a common lethal anomaly, occurring at least once in every thousand births $s^{1-3,35}$. Recent evidence proves that there is variation in the prevalence of anencephaly in time, place, and population to population ${ }^{16}$. In different times and regions, the prevalence of anencephaly ranges from one in every thousand births to one in every five thousand births. Income level and instituted folic acid fortification are the main factors that determine the prevalence of anencephaly in one country. A significant difference in the birth prevalence of anencephaly across countries was detected in this review. A very high (0.37\%) birth prevalence of anencephaly was detected 


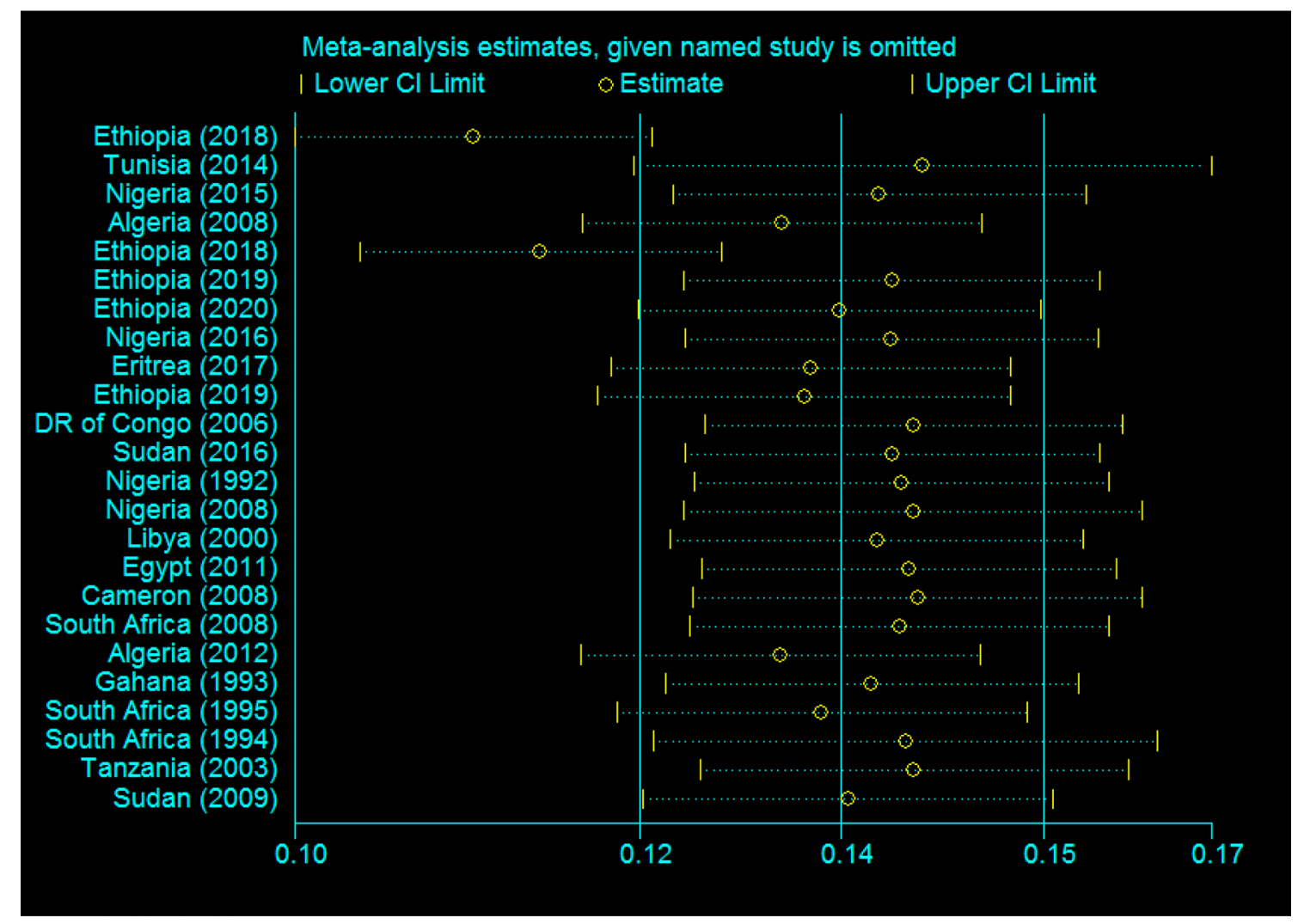

Figure 5. Sensitivity analysis to see the influence of each study in Africa, 2020.

\section{Time trend analysis}

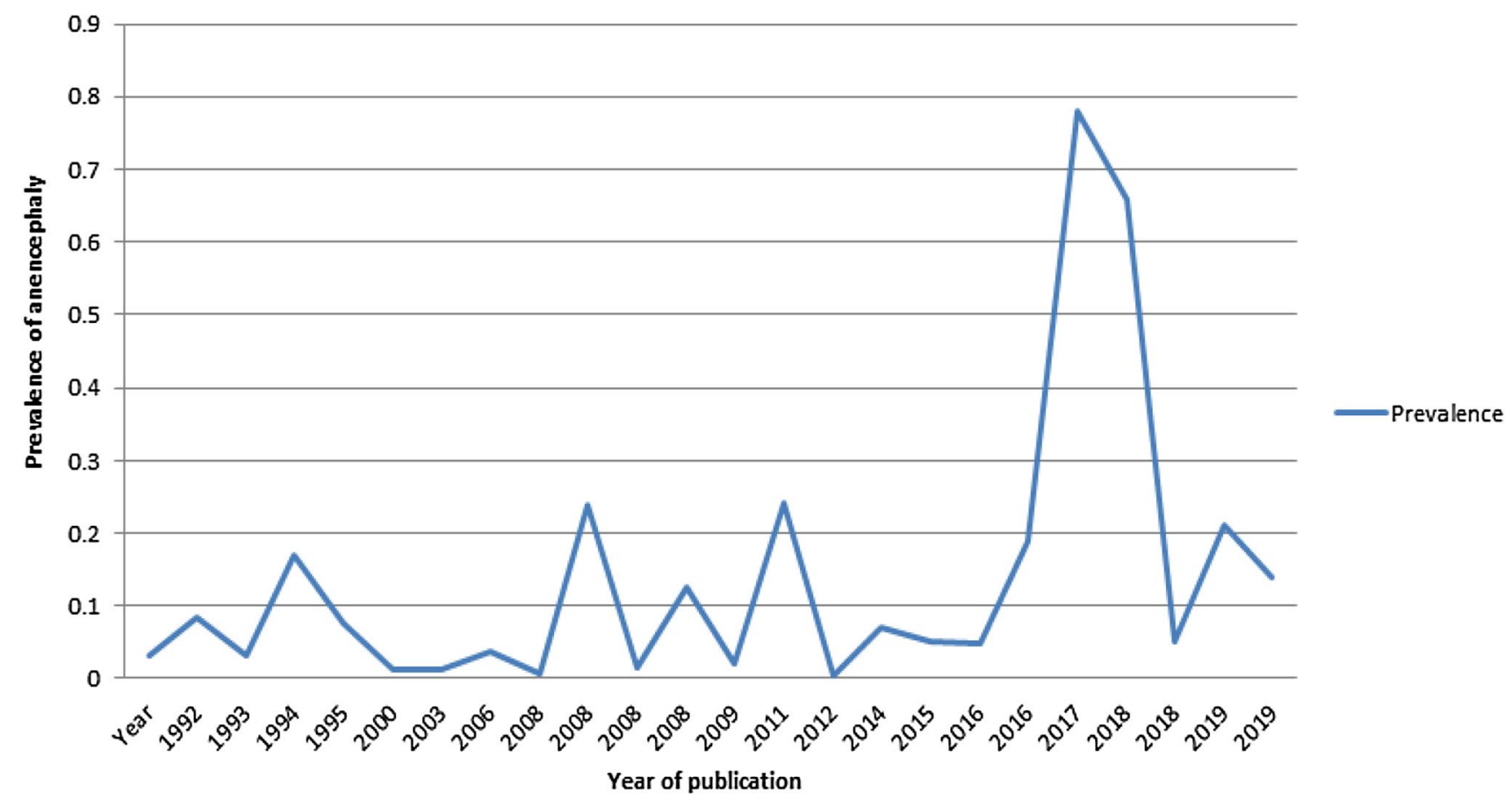

Figure 6. Time trend analysis of the prevalence of anencephaly in relation to publication year in Africa, 2020. 


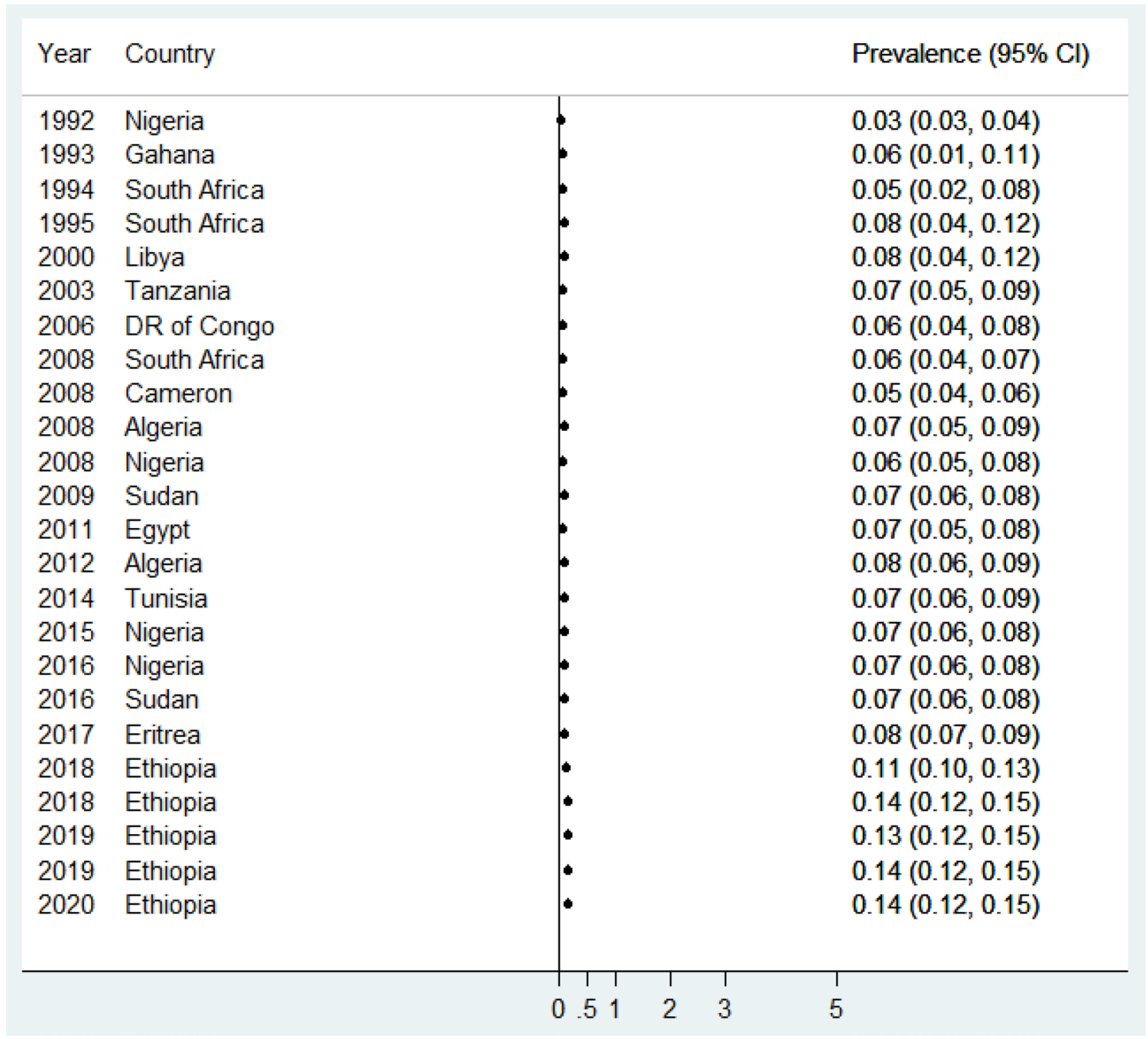

Figure 7. Meta-cumulative analysis of the prevalence of anencephaly in Africa, 2020.

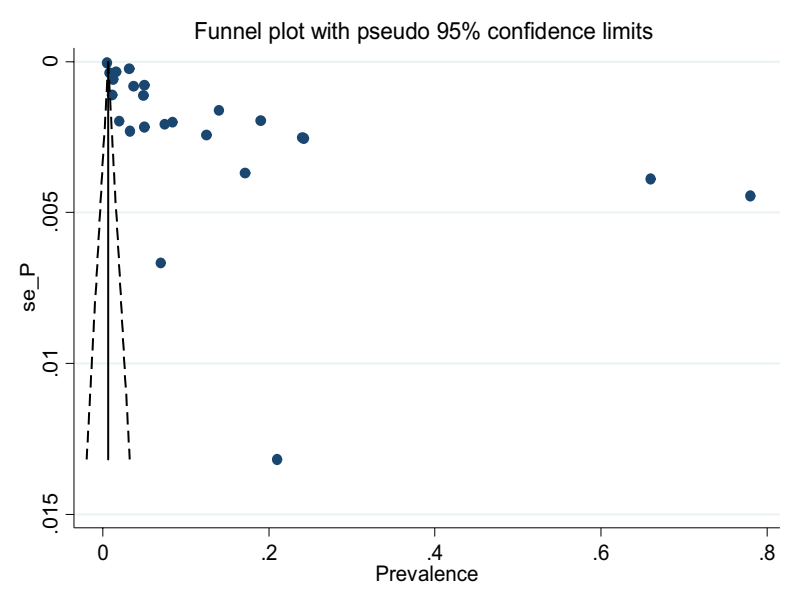

Figure 8. Funnel's publication bias plot, 2020.

in Ethiopia for example, the prevalence in Algeria was $0.24 \%$, and in Eritrea was $0.19 \%$. The lowest prevalence was detected in Tunisia (0.005\%). Maybe this difference among countries comes due to the levels of knowledge of mothers about folic acid supplementation, the country's health policies regarding folic acid fortification, and other preventive measures. Furthermore, the difference in prevalence estimate among countries may be due to the difference in the presence of robust surveillance systems that track all pregnancy outcomes (some studies 


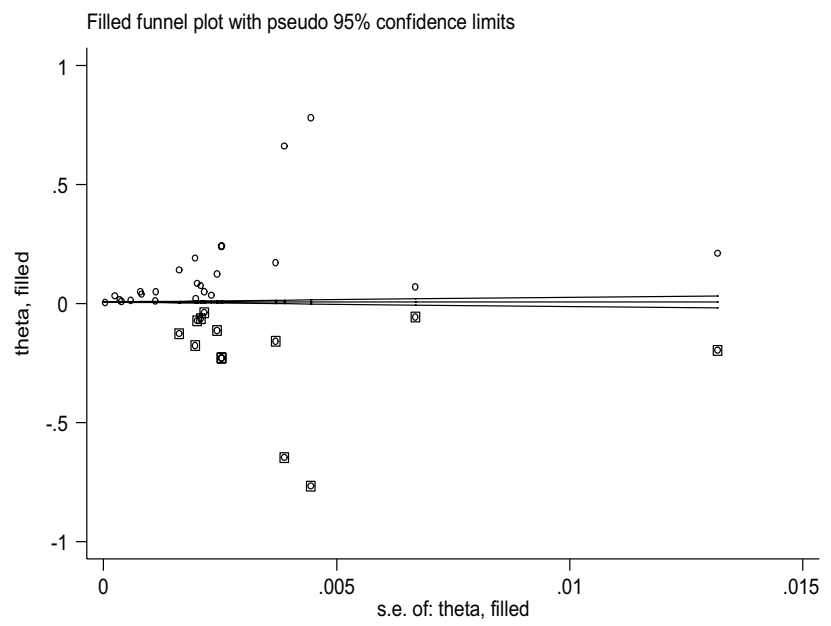

Figure 9. Trim and fill analysis of funnel plot to trim publication bias among studies, 2020.

may use a good surveillance and tracking system but others may not have tracked all births). These variations may underestimate the overall burden of anencephaly in Africa. The prevalence estimates were also affected by the difference of countries having access to antenatal screening and terminations. If the terminated cases of anencephaly during pregnancy are very high in one country, it is less likely to have high prevalence estimates at birth. Studies reported that the presence of wide geographical variation in prevalence estimates between the countries ${ }^{16}$. In Tunisia, the lowest prevalence may be related to the detection methods used, reporting and recording system, and the issue of terminated cases. Moreover, the adequacy of the sample size (extremely high sample size in Tunisian study) may affect the estimated report. In the present review, time trend analysis displayed that there was variation in different periods. The highest burden of anencephaly was observed between 2016 and 2018. This finding was also supported by a subgroup analysis of the period prevalence (high prevalence was detected after the year 2010). The increment in the prevalence of anencephaly in this duration may be due to a change in detection methods, an increment of the practices in documenting and reporting cases, an increase of the demands for fetal pathological examinations over these years, or a real increase in disease. The prevalence estimate in live births $(0.06 \%)$ was lower than estimates from both live births and stillbirths $(0.16 \%)$. Besides, the prevalence estimate is affected by the status of a mandatory folic acid fortification policy. Because all studies in the current review were hospital-based studies, an underestimation of the prevalence estimates should be noted, as the review did not consider many stillbirths and home births that are delivered in the community setting.

This review finding will help to improve the prevention and control programs in African countries. The severity of the defect, the observed differences in prevalence estimate among countries, may inform to modify the clinical and policy guidelines in the prioritization of interventions in Africa. It is remarkable if the next step will be that all African countries should adopt and implement a mandatory folic acid fortification policy. Besides, there should be started/improved robust surveillance systems in each country to track all pregnancy outcomes, particularly birth defects. Notably, this review highlight the birth prevalence of anencephaly in African countries, providing crucial evidence for policymakers, clinicians, and the concerned bodies who neglected the burden of this defect. The high burden detected in this review may initiate the policymakers to apply effective prevention strategies and may use their ultimate potential in reducing the burden of the anencephaly and making further research possible (additional clinical studies to focus on risk factors, prevention, intervention, and psychosocial outcomes of the defect in isolated form).

As many strengths of the review as it is, the outputs of the present review should be interpreted based on some limitations; the estimate did not include the terminated pregnancy/cases of anencephaly and this may decrease the prevalence estimates. Furthermore, the variability of the sample size in the included studies might influence the pooled birth prevalence estimates. Besides, the presence of significant variation across countries may underestimate the overall burden in Africa. Further, English-written articles were included in order to meticulously examine the quality of the articles. The review represented the studies from the twenty-four African countries due to limited available data about anencephaly.

\section{Conclusions}

The present systematic review and meta-analysis showed that a high birth prevalence of anencephaly was detected in Africa.

The birth-pooled prevalence of anencephaly was very high in Ethiopia and Algeria.

The higher pooled prevalence of anencephaly was observed in the studies included both live births and stillbirths and in studies done after the year 2010 whereas, the lower burden of anencephaly was detected among countries that had a mandatory folic acid fortification.

Therefore, we would like to inform policymakers that the pooled birth prevalence estimates are possible underestimates due to the lack of robust surveillance systems in Africa. The meta-analysis should not impact policy decisions on folic acid-based prevention efforts in Africa negatively where policymakers may feel that this 
is not a big enough problem for prioritizing prevention funds. Moreover, strong prevention and control measures should be the priority because of an increment in the magnitude of anencephaly, and limited available data on anencephaly in Africa informs the need for additional primary research that would improve the estimated prevalence of anencephaly and recommend favorable aid policies through maternal education on preventive measures. Helping in prevention programs, which should be the ultimate contribution of this study to the field.

\section{Methods}

Review outcome, reporting of the findings, and searching strategies. The outcome of the present review was the birth prevalence of anencephaly in Africa. Birth prevalence of anencephaly is defined as the number of anencephaly cases of live births and/or stillbirths at birth, after 28 weeks of gestation, (numerator) from the total number of births (live births and/or stillbirths) during the study period (denominator). Remarkably, we performed this review in accordance with the PRISMA 2020 (preferred reporting items for systematic reviews and meta-analysis) guidelines ${ }^{19}$ (Supplementary file 1). The PROSPERO registered the protocol of this review with a registration ID of CRD42021229940. Initially, to avoid duplication, we checked the unavailability of the systematic review and meta-analysis on the topic of interest in the JBI (Joanna Briggs Institute) Library, Cochrane Library, and DARE database. Then, we identified relevant studies via a search of databases like PubMed Central, PubMed/Medline, Science Direct, Web of Science, Embase, JBI Library, African Journals Online, WHO, CINAHL, UCSF, Scopus, and Cochrane Library up to September 14, 2020. Grey literature was retrieved using Google and advanced Google Scholar searches. Moreover, we navigated the reference lists of identified articles for additional eligible studies. The primary search was carried out in an advanced PubMed database (Supplementary file 2). The core search terms considered in all databases were anencephaly, "neural tube defects", newborns/live births/stillbirths, Africa, and other related terms.

Inclusion/exclusion criteria and study selection. Studies were eligible for inclusion if they reported the birth prevalence (live births and/or stillbirths) of anencephaly in Africa, studies in any setting, published and unpublished full-text studies in any period, studies reported in the English language, and study designs that reports the birth prevalence/incidence. All newborns with visible congenital neural tube anomaly/defect, anencephaly, identified through clinical evaluation (gross visual examination) by physicians, and/or diagnosed based on ICD-10 classifications, at the time or following the delivery after the twenty-eight weeks of gestation were considered anencephaly cases. Meanwhile, we excluded anonymous reports, conferences, editorials, case reports, and studies without full access (after contacting the author two times through email) from the review. Moreover, studies that did not contain appropriate prevalence data, for instance, review papers or studies providing only calculated estimates (without reporting appropriate numerator/denominator) were excluded. The Endnote Version 7.2 Software was used to import citations following the search of the databases. The three authors (MO, AG, and AA), independent of each other, selected all articles.

Study validity and data abstraction. We used the JBI quality appraisal checklist to examine the risk of bias in each study ${ }^{36}$. The checklist of studies reporting the prevalence data was considered to evaluate studies (it contains nine items) (Supplementary file 3). Remarkably, two authors (MO, AG) independently evaluate the quality of each study using the template. The discrepancies between authors that arise during examining the quality were solved based on discussions and/or by taking the average score of the two authors.

After including the eligible articles, three authors (AG, AA, and $\mathrm{MO}$ ) extracted all essential qualitative and quantitative data independently using a standardized, pre-specified, data abstraction template. The data abstraction format included main author, study design, publication year, sample size, study country, study setting, study duration, period prevalence, folic acid fortification policy, and birth prevalence (birth outcome: live births only, and both live births and stillbirths) of anencephaly. In this review, all studies' prevalence reports in the different denominators have been converted into per hundred births to maintain uniformity and we used per hundred estimates to report the findings. This was calculated directly from data when the appropriate number of cases and denominator were given.

Statistical analyses and meta-analyses. After extraction of the data in Microsoft Excel and we exported it into STATA Version 14 Statistical Software for further analyses. In addition to the main analysis, we estimated the median value and interquartile range for all included studies. The heterogeneity between the studies was examined using the Cochran $\mathrm{Q}$ test and $\mathrm{I}^{2}$ test statistics ${ }^{37}$. Due to the significant heterogeneity $(P$ value $<0.001)$, it was decided that estimating a weighted average (via the random-effect meta-analysis model) was the best approach to obtaining the pooled prevalence estimates ${ }^{38,39}$. Furthermore, meta-analyses were carried out separately for each sub-group: birth prevalence based on the study country, study design, birth outcome, period prevalence, and folic acid fortification status. In subgroup analysis, if significant heterogeneity across the subgroups was detected, the Der Simonian and Laird's $(D+L)$ pooled prevalence method was considered because it is more conservative (can lead to reliable estimates) than the inverse variance method (I-V). The Forest plot was used to display the presence of heterogeneity among the studies. Meta-regression analysis, sensitivity analysis, time-trend analysis, and meta-cumulative analysis were performed as well. To assess the publication bias, funnel plot asymmetry was used. Essentially, the trim and fill analyses were considered to mitigate the publication bias.

\section{Data availability}

The data sets used and/or analyzed during the current systematic review and meta-analysis are available from the corresponding author on reasonable request. 
Received: 22 January 2021; Accepted: 24 November 2021

Published online: 09 December 2021

\section{References}

1. Moore, K. L. \& Persaud, T. V. N. Chapter: Congenital anomalies of the brain and spinal cord Saunders. In The Developing Human. Clinically Oriented Embryology 8th edn.

2. Sadler, T. W. Chapter: Clinical correlates in central nervous system embryology. In Langman's Medical Embryology (eds. Sadler, T. W.), 11th edn.

3. Sadler, T. W. Chapter: Clinical correlates in central nervous system embryology. In Langman's Medical Embryology (eds. Crystal Taylor), 12th edn. (Wolters Kluwer, Lippincotte Williams and Wilkins, 2011).

4. Chandrupatla, M. \& Swargam, N. Anencephaly: A case report. Int. J. Sci. Stud. 2(7), 255-257 (2014).

5. Gedefaw, A., Teklu, S. \& Tilahun, B. T. Magnitude of neural tube defects and associated risk factors at three teaching hospitals in Addis Ababa, Ethiopia. Hindawi BioMed Res. Int. Article ID 4829023, 10 pages (2018). https://doi.org/10.1155/2018/4829023.

6. Nasri, K. et al. Epidemiology of neural tube defect subtypes in Tunisia, 1991-2011. Pathol. Res. Pract. https://doi.org/10.1016/ jprp201406027 (2014).

7. Anyanwu, L. C., Danborno, B. \& Hamman, W. O. The prevalence of neural tube defects in live born neonates in Kano, NorthWestern Nigeria. Sub-Saharan Afr. J. Med. 2, 105-109 (2015).

8. Houcher, B., Bourouba, R., Djabi, F. \& Houcher, Z. The prevalence of neural tube defects in Sétif University Maternity Hospital, Algeria-3 years review (2004-2006). Pteridines 19, 12-18 (2008).

9. Berihu, B. A. et al. High burden of neural tube defects in Tigray Northern Ethiopia: Hospital-based study. PLoS ONE 13(11), e0206212. https://doi.org/10.1371/journalpone0206212 (2018).

10. Taye, M., Afework, M., Fantaye, W., Diro, E. \& Worku, A. Congenital anomalies prevalence in Addis Ababa and the Amhara region, Ethiopia: A descriptive cross-sectional study. BMC Pediatr. 19, 234 (2019).

11. Abebe, S., Gebru, G., Amenu, D. \& Dube, L. Prevalence and patterns of birth defects among newborns in Southwestern Ethiopia: Retrospective study. Res. Square. Preprint. https://doi.org/10.21203/rs.2.17559/v2 (2020).

12. Nnadi, D. C. \& Singh, S. The prevalence of neural tube defects in North-West Nigeria. Saudi J. Health Sci. 5, 6-10 (2016).

13. Estifanos, D. et al. The prevalence, trend, and associated demographic factors of neural tube defects at Orotta National Referral Maternity Hospital, Asmara: Retrospective record review study. Sci. J. Public Health 5(6), 452 (2017).

14. Legesse, A., Zawidneh, D., Gorfu, Y. Assessment of prevalence, types and associated risk factors of neural tube defects in pregnant women visiting health centers in Addis Ababa. http://213.55.95.56/bitstream/handle/123456789/20545/Aga\%20Legesse\%20.pdf? sequence $=1$ \&isAllowed $=y(2019)$.

15. Bhide, P., Gurdeep, S., Sagoo, G. S., Moorthie, S. \& Kar, A. Systematic review of birth prevalence of neural tube defects in India. Birth Defects Res. (Part A) 97, 437-443 (2013).

16. Rosenthal, J. et al. Neural tube defects in Latin America and the impact of fortification: A literature review. Public Health Nutr. 17(3), 537-550 (2013).

17. Czeizel, A. E. \& Dudas, I. Prevention of the first occurrence of neural-tube defects by periconceptional vitamin supplementation. N. Engl. J. Med. 327(26), 1832-1835 (1992).

18. Berry, R. J. et al. Prevention of neural-tube defects with folic acid in China. N. Engl. J. Med. 341(20), 1485-1490 (1999).

19. Page, M. J. et al. The PRISMA 2020 statement: An updated guideline for reporting systematic reviews. BMJ 372, n71. https://doi. org/10.1136/bmj.n1171 (2021).

20. Ahuka, O. L., Toko, R. M., Omanga, F. U. \& Tshimpanga, B. J. Congenital malformations in the North-Eastern Democratic Republic of Congo during civil war. East Afr. Med. J. 8, 95-99 (2006).

21. Omer, I. M., Abdullah, O. M., Mohammed, I. N. \& Abbasher, L. A. Research: Prevalence of neural tube defects Khartoum, Sudan August 2014-July 2015. BMC Res. Notes 9, 495. https://doi.org/10.1186/s13104-016-2298-6 (2016).

22. Airede, K. I. Neural tube defects in the middle belt of Nigeria. J. Trop. Pediatr. 38, 27-30 (1992).

23. Ekanem, T. B. et al. Prevalence of congenital malformations in Cross River and Akwa Ibom states of Nigeria from 1980-2003. Congenit. Anom. 48, 167-170. https://doi.org/10.1111/j17414520200800204x (2008).

24. Singh, R. \& Al-Sudani, O. Major congenital anomalies at birth in Benghazi, Libyan Arab Jamahiriya, 1995. East. Mediterr. Health J. 6, 65-75 (2000).

25. Mohammed, Y. A., Shawky, R. M., Soliman, A. A. \& Ahmed, M. M. Chromosomal study in newborn infants with congenital anomalies in Assiut University hospital: Cross-sectional study. Egypt. J. Med. Hum. Genet. 12, 79-90 (2011).

26. Njamnshi, A. K. et al. Neural tube defects are rare among black Americans but not in sub-Saharan black Africans: The case of Yaounde-Cameroon. J. Neurol. Sci. 270, 13-17 (2008).

27. Sayed, A. R., Bourne, D., Pattinson, R., Nixon, J. \& Henderson, B. Decline in the prevalence of neural tube defects following folic acid fortification and its cost-benefit in South Africa. Birth Defects Res. A 82, 211-216 (2008).

28. Houcher, B., Akar, N., Begag, S. \& Egin, Y. Neural Tube Defects in Algeria (INTECH Open Access Publisher, 2012).

29. Anyebuno, M., Amofa, G., Peprah, S. \& Affram, A. Neural tube defects at Korle Bu Teaching Hospital, Accra, Ghana. East Afr. Med. J. 70, 572-574 (1993).

30. Venter, P. A., Christianson, A. L., Hutamo, C. M., Makhura, M. P. \& Gericke, G. S. Congenital anomalies in rural black South African neonates-a silent epidemic?. S. Afr. Med. J. 85, 15-20 (1995).

31. Buccimazza, S. S., Molteno, C. D., Dunne, T. T. \& Viwoen, D. Prevalence of neural tube defects in Cape Town, South Africa. Teratology 50, 194-199 (1994).

32. Kinasha, A. D., Manji, K. P. The incidence and pattern of neural tube defects in Dar es Salaam, Tanzania. Eur. J. Pediatr. Surg. Suppl. 12, S38-S39 (2003).

33. Elsheikh, G. E. A. \& Ibrahim, S. A. Neural tube defects in Omdurman Maternity Hospital, Sudan. Khatoum Med. J. 2, 185-190 (2009).

34. Annie, L., Dora, P. \& Simrita, S. Estimating the burden of neural tube defects in low- and middle-income countries. J. Global health 4(1), $010402(2014)$.

35. Salih, M. A., Murshid, W. R. \& Seid Ahmed, M. Z. Epidemiology, prenatal management, and prevention of neural tube defects. Review article. Saudi Med. J. 35(Suppl 1), S15-S28 (2014).

36. Moola, S., Munn, Z., Tufanaru, C., Aromataris, E., Sears, K., Sfetcu, R., Currie, M., Qureshi, R., Mattis, P., Lisy, K. et al. Chapter 7: Systematic reviews of etiology and risk. In Joanna Briggs Institute Reviewer's Manual (eds. Aromataris, E., Munn, Z.) (The Joanna Briggs Institute, 2017). Available from https://www.reviewersmanualjoannabriggs.org/

37. Higgins, J. P., Thompson, S. G., Deeks, J. J. \& Altman, D. G. Measuring inconsistency in meta-analyses. Br. Med. J. 327(7414), 557. https://doi.org/10.1136/bmj3277414557 (2003).

38. Munn, Z., Moola, S., Lisy, K., Riitano, D. \& Tufanaru, C. Methodological guidance for systematic reviews of observational epidemiological studies reporting prevalence and incidence data. Int. J. Evid. Based Healthc. 13(3), 147-153 (2015).

39. Borenstein, M., Hedges, L. V., Higgins, J. \& Rothstein, H. R. A basic introduction to fixed-effect and random-effects models for meta-analysis. Res. Synth. Methods 1(2), 97-111. https://doi.org/10.1002/jrsm12 (2010). 


\section{Author contributions}

M.O., A.T., and M.S. participated in the conceptualization of the review protocol, formal analysis, methodology or study design, writing-original draft, interpretation, writing-review and editing, and approving the final draft. A.G., M.O., and A.A.: Quality assessment, study selection, data extraction, and literature review. All authors read and approved the manuscript.

\section{Competing interests}

The authors declare no competing interests.

\section{Additional information}

Supplementary Information The online version contains supplementary material available at https://doi.org/ 10.1038/s41598-021-02966-w.

Correspondence and requests for materials should be addressed to M.O.

Reprints and permissions information is available at www.nature.com/reprints.

Publisher's note Springer Nature remains neutral with regard to jurisdictional claims in published maps and institutional affiliations.

(c) (i) Open Access This article is licensed under a Creative Commons Attribution 4.0 International License, which permits use, sharing, adaptation, distribution and reproduction in any medium or format, as long as you give appropriate credit to the original author(s) and the source, provide a link to the Creative Commons licence, and indicate if changes were made. The images or other third party material in this article are included in the article's Creative Commons licence, unless indicated otherwise in a credit line to the material. If material is not included in the article's Creative Commons licence and your intended use is not permitted by statutory regulation or exceeds the permitted use, you will need to obtain permission directly from the copyright holder. To view a copy of this licence, visit http://creativecommons.org/licenses/by/4.0/.

(c) The Author(s) 2021 